\title{
MUSINT II: a complex project on a virtual and interactive museum involving institutions in Florence, Rome and Heraklion
}

\author{
ANNA MARGHERITA JASINK, CRISTIAN FARALLI, PANAIOTIS KRUKLIDIS \\ University of Florence, Italy
}

\begin{abstract}
MUSINT II is part of a more general project on a series of virtual and interactive museums, using traditional and new technologies with the aim of reaching a wider audience. An interdisciplinary methodology provided by the participation of archaeologists, architects/designers and computer scientists makes the project rich in attractive solutions for visitors of different levels. MUSINT II uses a sophisticated structure, a series of 3-dimensional models produced with both photogrammetry and laser scanning. A complex database with many interconnected queries was implemented to make the study of a large number of objects more efficient and to offer truly innovative research responses with effortless data processing. New hyperrealistic techniques are used to best illustrate the reconstruction of buildings, objects and scenes of life. A specific educational section is addressed to young people, with all these new techniques applied in a winning way. The main object of MUSINT II is a specific category of small objects, sealings and seals, coming from the excavations at Haghia Triada carried out by the Italian Archaeological expedition in Crete at the beginning of 1900 . Our purpose is to offer a new analytic and, at the same time, synthetic vision, addressed to a wide audience, of the historical and archaeological representation of one of the most important sites of Minoan Crete.
\end{abstract}

\section{Keywords:}

Interactive Museum, Aegean Civilizations, Technological Methodologies.

\section{SDH Reference:}

Anna Margherita Jasink et al., MUSINT II: a complex project on a virtual and interactive museum

involving institutions in Florence, Rome and Heraklion, 2017. SDH, 1, 2, 282-297.

DOI : 10.14434/sdh.v1i2.23192

\section{INTRODUCTION}

The development of new technologies and their application in the general field of cultural heritage has opened new perspectives also in museology [Economou 2006; Hermon and Nicolucci 2007; Oberländer-Târnoveanu 2008; EPOCH project at http://epoch-net.org/site/] to such an extent that the very idea of the museum has evolved from a traditional static form, conceived for the direct observation of artifacts to a more dynamic and interactive concept that goes beyond the single site exhibition. The individual traditional museum has been digitally duplicated to make it accessible

Author's address: A. M. Jasink, University of Florence, Via San Gallo 10, Florence, Italy; email: jasink@unifi.it; C. Faralli email: cristianfaralli@gmail.com; P. Kruklidis email: panaiotiskruklidis@gmail.com

Permission to make digital or hardcopies of part or all of this work is granted without fee according to the open access policy of SDH.

(C) 2017 SDH Open Access Journal 
online. Exploiting advanced digital communication tools, it is possible to go beyond the simple "replica" of the museum to show the intrinsic properties of the artifacts, hidden aspects not visible at first sight, such as the original geographical or historical location of their creation and other information accessible through dedicated databases, in some cases with recorded interviews with curators. These important advances are still confined in the domain of a static vision of the museum, although with a delocalized access; the main function of the interaction is to offer the possibility of browsing through collections and choosing which item to view. The best examples are obviously those of the British Museum and of the Louvre, with huge collections and various databases available online, educational content for children and special focus on selected items. The virtual museum [Djindjan 2007; Mancini 2008; Antoniou et al. 2016] can arise as an autonomous digital entity ensuring on the one hand general free access on the web and on the other hand enhancing the traditional museum experience through personalization, interactivity and richness of content. This has been accomplished by full recourse to new technologies [Stanney \& Hale 2014]. It is quite evident that the virtual museum is particularly suited for applications in archaeology [Moscati 2007; Artusi et al. 2010]. New imaging methods [Remondino 2011] allow for an augmented and more significant representation of the artifacts. In addition, the virtual museum provides the audience with extended and integrated information on the site of the finds, their history and their cultural context. Finally, it allows the simultaneous exhibition of finds stored in different museums or locations, resulting in a more complete understanding of materials. To explore these and other applications for archaeology is the aim of the Virtual Museum Transnational Network V-MUST (2011-2015) (http://www.Vmust.net/).

This paper deals with MUSINT, the first application of the virtual museum to Aegean archaeology (Bronze Age Greece). So far, this sector of studies has been variously illustrated through augmented reality techniques: see, e.g., the reconstruction of Hall 64 of the Pylos palace, Messenia (http://classics.uc.edu/prap/Hall64.html). The most important Bronze Age findings from the largest Museum collections of Greece are now available online, thanks to the Latsis Foundation Museum Cycle (http://www.latsis-foundation.org/eng/education-science-culture/culture/the-museumscycle). However, this is simply the online transposition of actual printed catalogues, without any possibility of interaction. No Aegean site or project figures in the V-MUST Network, though various examples from classical Greece are represented. Actually, a proper virtual museum is still missing and MUSINT is the first attempt in this direction.

This is why, in recent years, we developed a research project (MUSINT) on virtual and interactive museums of Aegean civilizations with the goal of reaching a wide audience, combining traditional methods and new technologies [Jasink, Tucci and Bombardieri 2011]. The virtual museum is accessible on www.aegean-museum.it or www.dbas.sciant.unifi.it website (www.aegeanmuseum.it/musint2/it for MUSINT II). The project includes the joint contribution of archaeologists and historians, to define the subject-matter and to write accurate texts; of architects/designers, to ensure enhanced standards of pictorial and graphic representation; and of computer scientists, to guarantee a smooth and effective connection between content and display. The intrinsic multidisciplinary approach made the project attractive to different visitors due to the variety of available pathways. In a previous CHNT meeting, an application of MUSINT to the teaching of ancient history in primary schools was discussed [Dionisio and Jasink 2016]. 
In the present paper, MUSINT II, a major addition to the general project, is described. Technological methods and interactive devices have been more extensively exploited to present specific historical and archaeological topics at a high scientific level on the one hand and for a non-specialized audience on the other. MUSINT II is accessible on the websites given above. The core of the new project is the collection of small clay objects from the Neopalatial Villa of Haghia Triada, one of the main Cretan sites, which flourished in the middle of the 2nd millennium BC. This is the period of full development of the Minoan civilization. While the topic of the new project is more limited, the potential audience is definitely wider. In fact, the new museum is structured in two sections, the first addressed to scientists and curious adults and the second with explicit educational aims.

The cretulae or nodules we are dealing with represent, together with the tablets, the administrative documents of the period and may bear both sealings and signs carved in Linear A script. These small objects were discovered at the beginning of the 1900s during excavations by the Italian Archaeological expedition in Crete, specifically devoted to the Phaistos and Haghia Triada sites. The majority of these finds remained in Crete, in the Heraklion Archaeological Museum, while others were taken to Italy and are presently stored in the National Archaeological Museum of Florence and in the Prehistoric-Ethnographic Pigorini Museum in Rome, the latter named after its founder Luigi Pigorini (see Fig. 1).

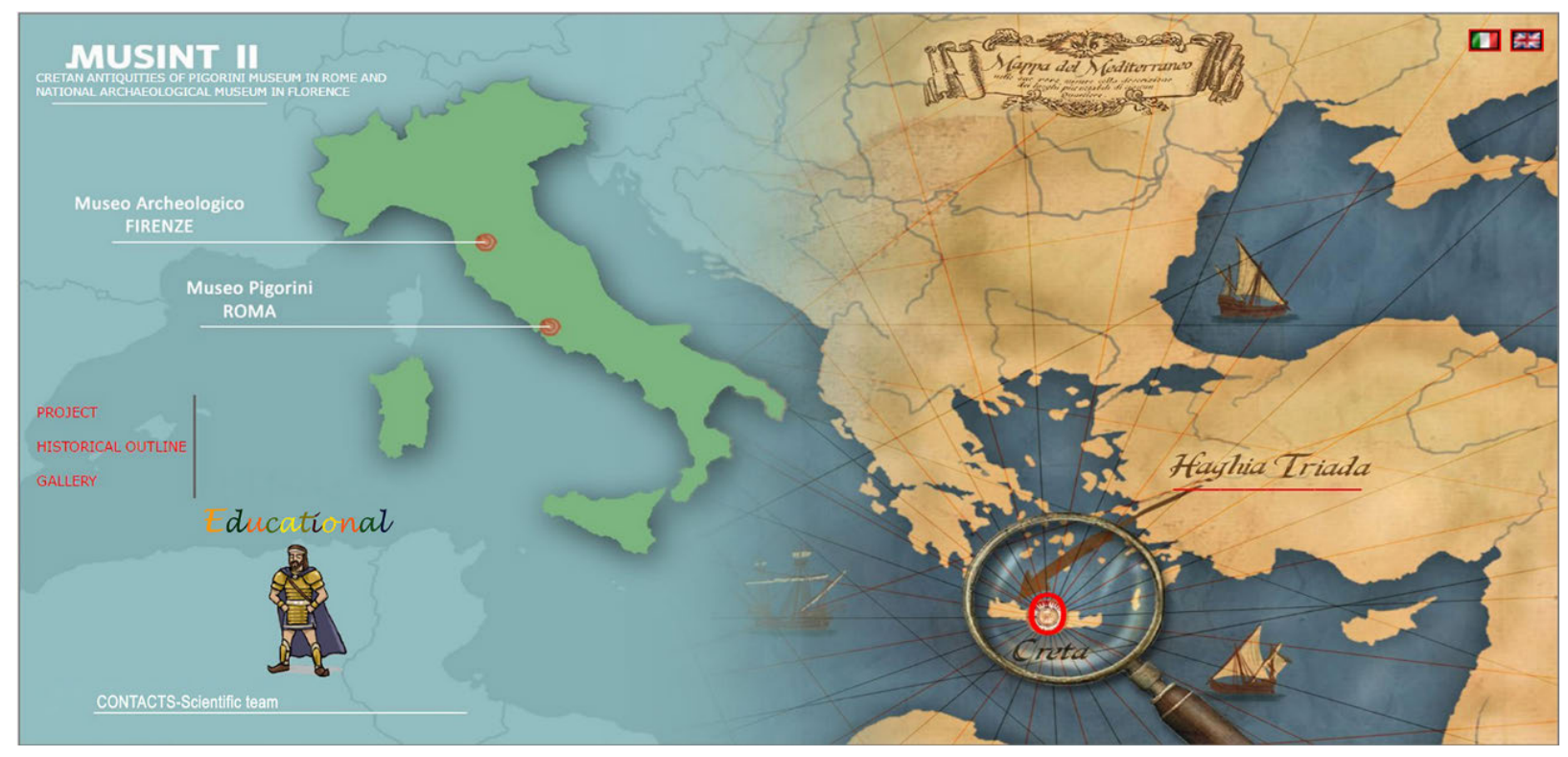

Figure 1. Home page of MUSINT II

These documents have been repeatedly analyzed since their discovery. The novelty of the present project is to make the items from the three locations simultaneously available in the single virtual Museum of MUSINT II while retaining their individuality. This is not only a useful and simplified tool for researchers but it is also a unique opportunity for other visitors to get a full idea of the Minoan administrative system. 
Figure 1 shows the interactive map of the home page. On the right side, Crete and the site of Haghia Triada, where the objects were found, are highlighted. On the left side, the two Italian collections and their conservation sites are shown. Just below, an animated icon, an Aegean warrior, provides access to the educational section, mainly, but not only, addressed to primary school pupils. Moreover, a brief historical introduction to Bronze Age Crete is given ("Historical outline").

All web pages are characterized by a common graphics with rich and attractive details. The page layout is designed with a full colored background, with communicative images and animations. The color palette is decided in advance and an independent style for each page is obtained with appropriate colors. Photographs, drawings and reconstructions recall the style of the general MUSINT project and move on two parallel but different tracks, as required by appropriate approaches to scientific and educational sections.

\section{HAGHIA TRIADA}

The Haghia Triada webpage, from which five different items can be explored, is shown in Figure 2 .

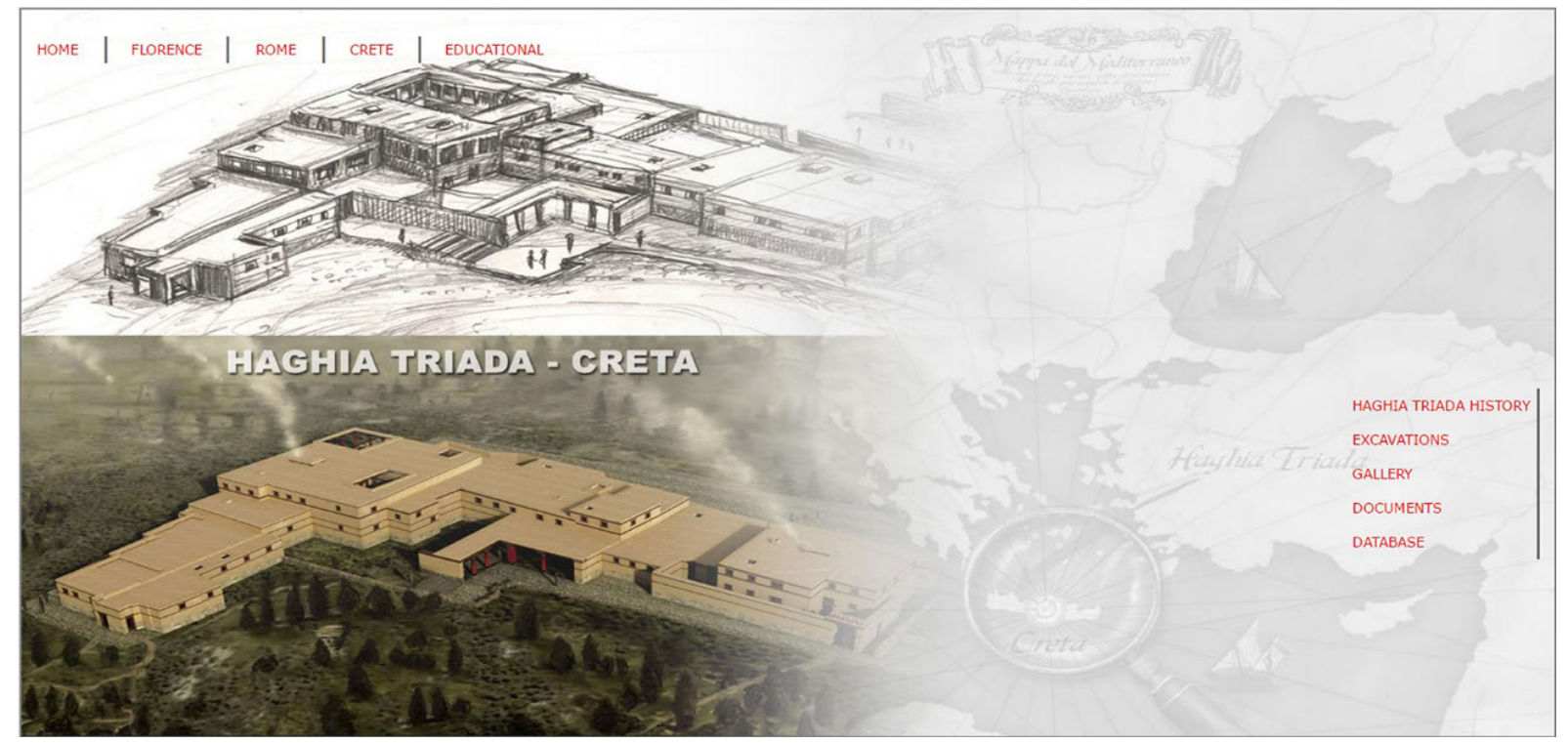

Fig. 2. Home page of the "Haghia Triada" website

a. Haghia Triada History. Various phases of the archaeological site, which developed throughout the Bronze Age (Prepalatial, Protopalatial, Final/Monopalatial, Postpalatial periods), can be explored, with particular attention to the Neopalatial period, to which the sealed documents refer.

b. Excavations. This page is concerned with Italian archaeological missions in Crete and the story of the protagonists of this adventure is also briefly described. Reading the information provided has been improved and made easier by using the so-called "popup windows" written in Javascript. This programming language is considered one of the most powerful tools for improving a website with 
dynamic and interactive applications. Javascript code is perfectly embedded in HTLM-PHP languages normally used to build websites. Javascript popup windows are successfully used in the MUSINT II website to open pages containing biographies with pictures and other images, without compromising the understanding of the text [Faralli 2016].

c. Documents. Administrative documents are described, including tablets and sealed brief inscriptions. The latter documents, in particular the Florentine and Roman pieces, are the core of MUSINT II, as will be seen in the following. They are small clay pieces with an impressed seal on one side and, often, a symbol in Linear A script on another face, as shown in Figure 3.

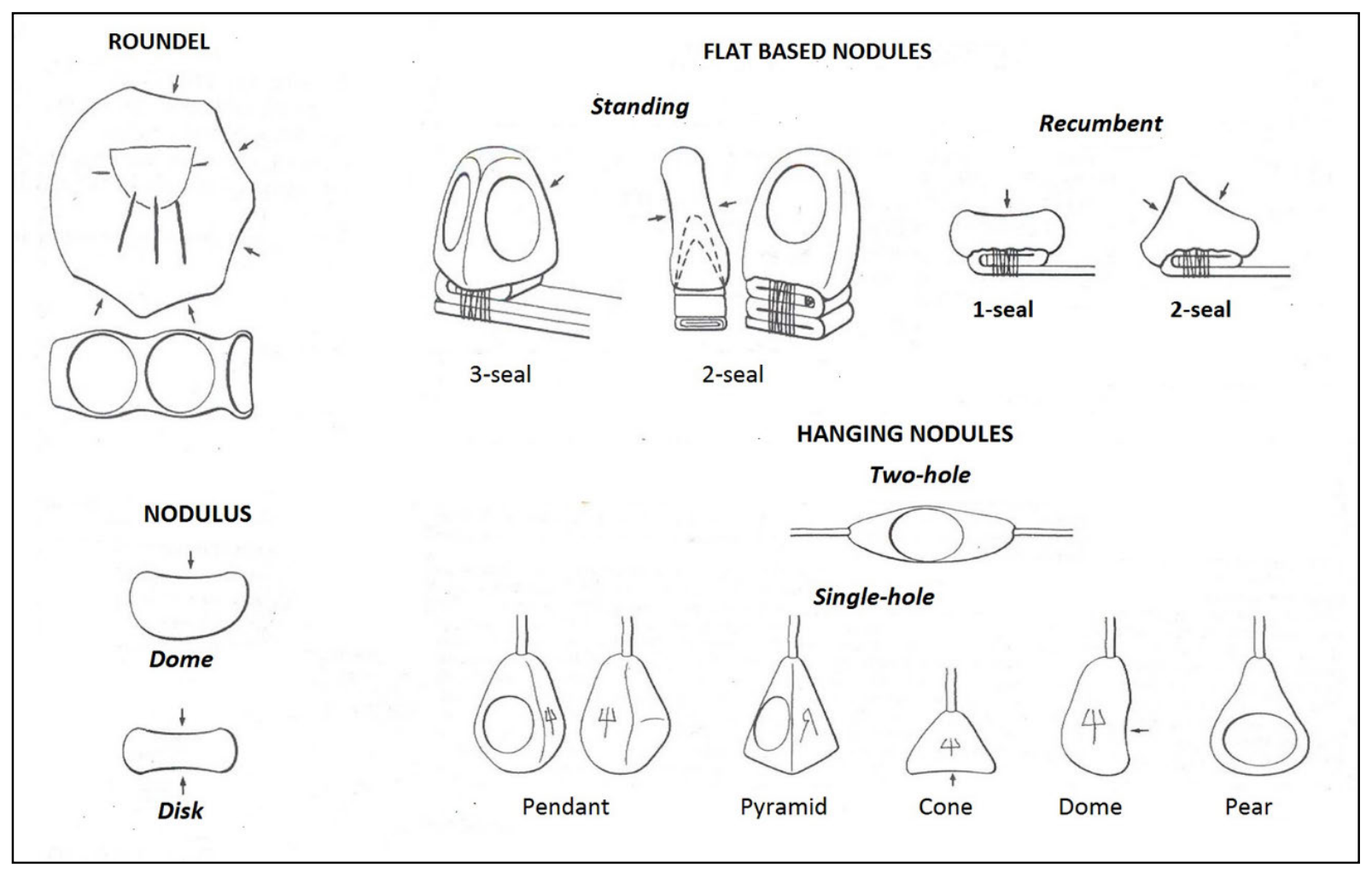

Figure 3. Typologies of the administrative sealed documents from Haghia Triada (modified from HALLAGHER 1996)

d. Database. This database is one of the most innovative aspects of MUSINT II. The relational database management system used is MySQL. This system is very useful for managing dynamic websites. MySQL is fully supported by most of the programming languages, such as PHP. The interaction between the database and the web pages is achieved by using the SQL language to construct the queries and to recover the data. This architecture has been successfully used in a well-known application in the Aegean field [Arachne: http://arachne.uni-koeln.de/], which concerns the whole corpus of Minoan and Mycenaean seals. Along the same lines we have already been able to enter into an extremely more elaborate analysis of a specific sector of the seals [DBAS CHS - Cretan 
Hieroglyphic Seals: http://www.sagas.unifi.it/vp-394-dbas-chs-cretan-hieroglyphic-seals.html], to sort out useful statistical information.

The present database improves considerably the study of the Haghia Triada sealed documents. First of all, it gathers in a unified digital catalogue the information on the seals and on written signs, which have been separately published in the basic volumes CMS II 6 and GORILA 2, respectively. In addition, it allows extensive and overlapping cross-correlations that can lead to new interpretations of both seals and written signs.

Dedicated files to single cretulae with a stamped seal and, very often, with carved script signs, constitute the starting point for entering into new and diversified routes by means of distinct but connected queries, which try to answer as many questions as possible. This relational database allows users to consult the information about shape, motifs, inscriptions and so on of single objects and to make queries to correlate such information; it also provides statistical data (percentages, recurrences, and so on).

A more detailed discussion of the structure of this database will appear in a forthcoming paper by Alberti, Faralli and Jasink.

This specific project on materials that have already been widely analyzed has been conceived not as a mere instrument but as a scientific study capable of contributing to our knowledge of the administrative system, of the figurative arts and of the daily life of the Minoan Neopalatial society, at least in Haghia Triada.

e. Gallery. Photos, maps and drawings complete the Haghia Triada section.

\section{THE ITALIAN MUSEUMS}

In the present section, we consider the web pages (shown in Figure 4) of the museums in Florence and Rome that have been worked out with equal criteria but show some differences in two of the three sub-sections.

A significant difference is found in the "Collections." The Roman one consists solely of materials from Crete, while the Florentine collection includes the whole Aegean world - Crete, Greece, Cyclades, Rhodes and, in addition, Cyprus-, including Neolithic and Bronze Age objects as well. The Pigorini Museum of Rome received many more objects from the Italian Mission in Crete than the Florentine Museum. But in Florence, the director of the Archaeological Museum, Luigi Adriano Milani, in the years between the end of the 19th century and 1910, was in contact with various merchants and archaeological institutions, and bought or traded objects which enriched the Florentine "Aegean Collection." In Florence, therefore, materials from Haghia Triada are not as abundant as in Rome [Jasink and Bombardieri 2009; Jasink, Tucci and Bombardieri 2011; MUSINT website]. 


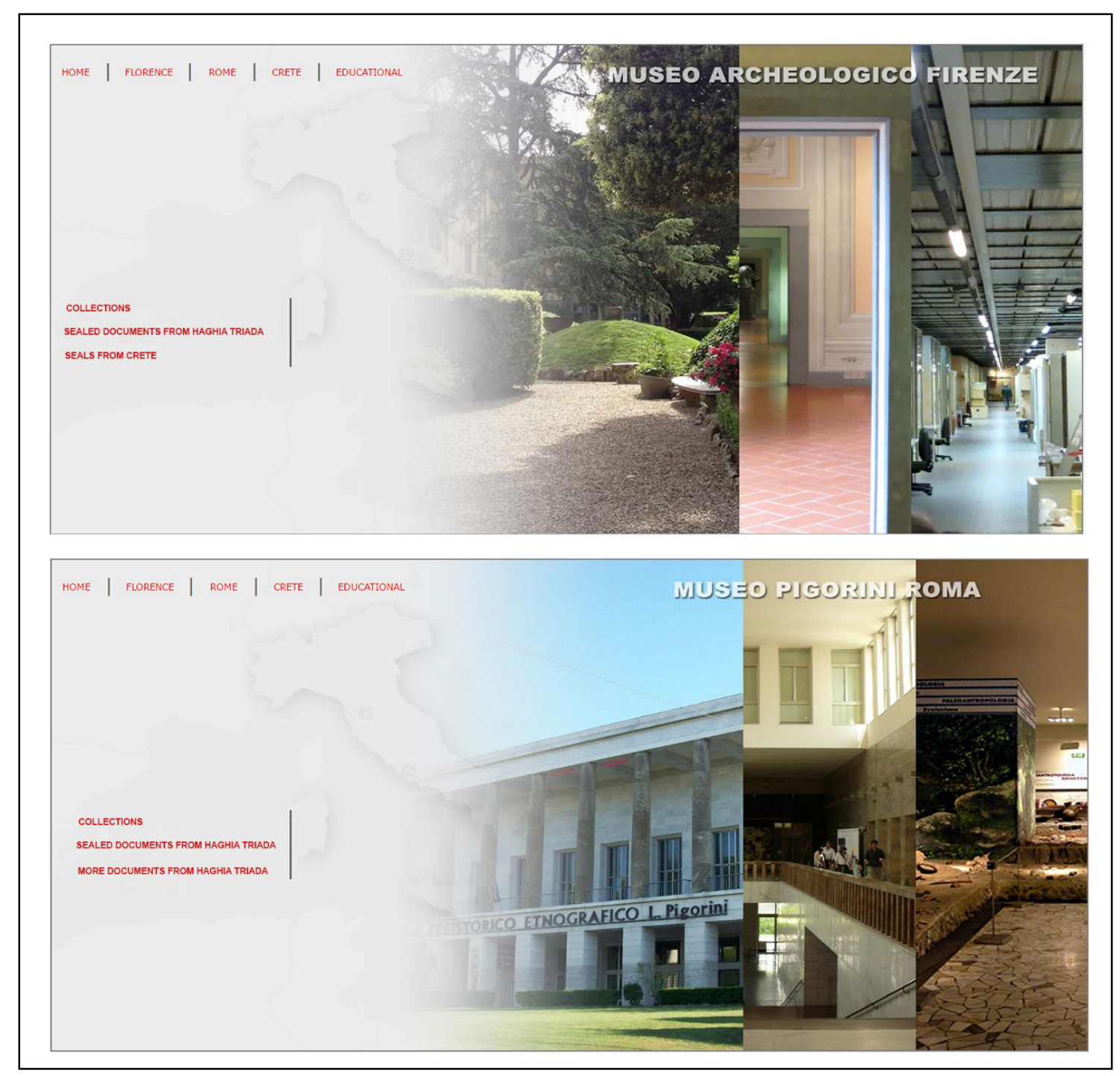

Figure 4. Web pages of the two Italian Museums with Minoan Collections

This explains the difference of the third item introducing the web pages on the two Museums: "More Documents from Haghia Triada" for Rome and "Seals from Crete" for Florence. The first includes documents (three tablets and one pithos), which differ from cretulae, but still come from Haghia Triada and may be considered as administrative and written sources. The second is made up of a series of seals that came to the Florentine museum through different routes and range from the Minoan Prepalatial to the last Mycenaean period (Figure 5). These have been included in MUSINT II to complete the Italian collection of Aegean seals, the seals are presented in MUSINT II as 3D models, in the same way as the sealings. A more detailed discussion about 3D structure and the photogrammetry methodologies is dealt with in another paper in this same volume [Marziali and Dionisio 2017] and in other articles [Pitzalis et al. 2007; Sotoodeh et al. 2008]. 


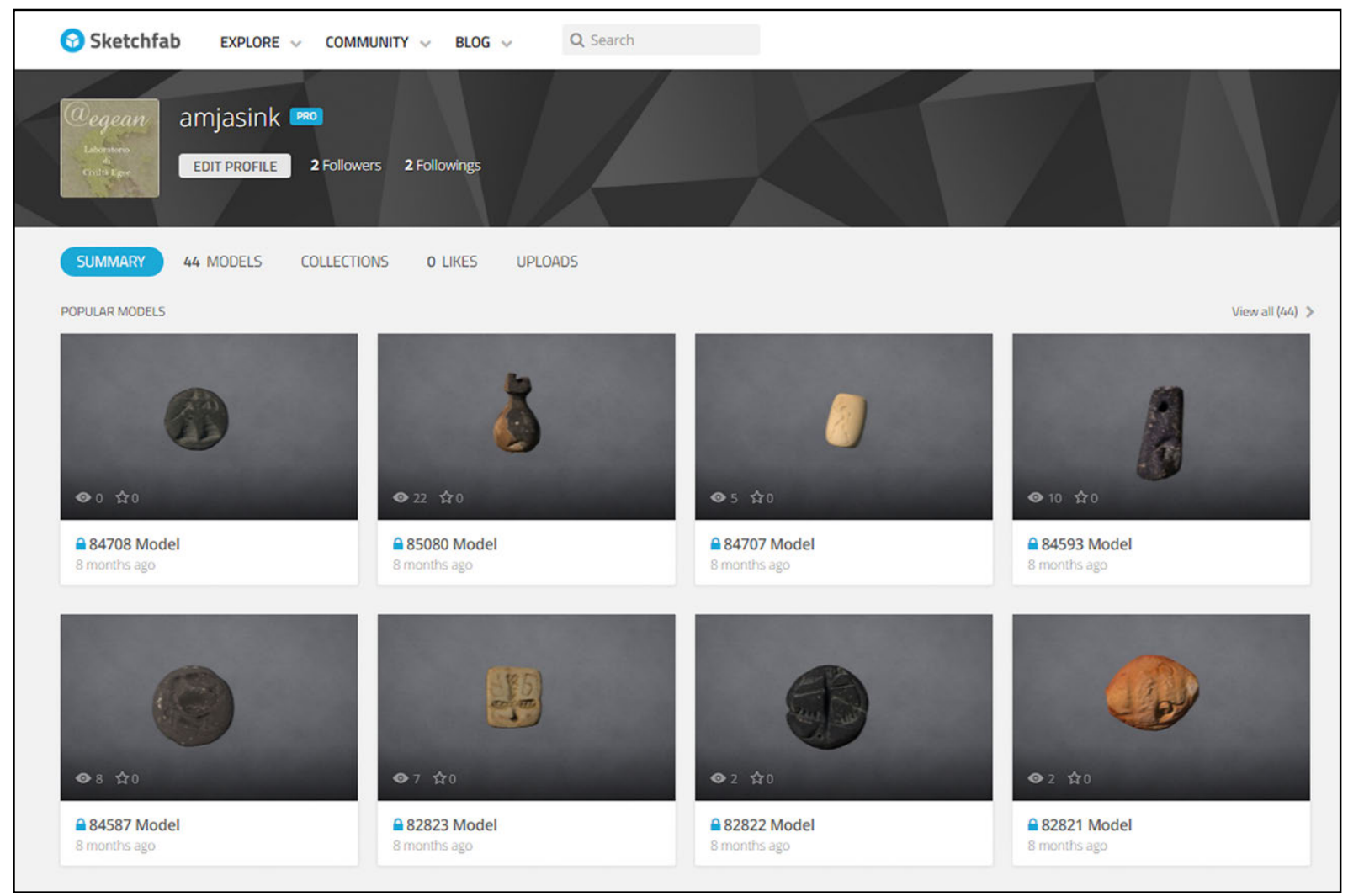

Figure 5. Examples of seals of the Aegean collection in Florence

As discussed above, the core of MUSINT II is represented by the files made available in the subsection "Sealed documents from Haghia Triada," which has the same structure for the two museums. A dedicated file, containing a descriptive table with detailed information and, whenever possible, a 3D image, has been uploaded for each object (Figure 6). For the descriptive tables, reference can also be made to the general Haghia Triada database.

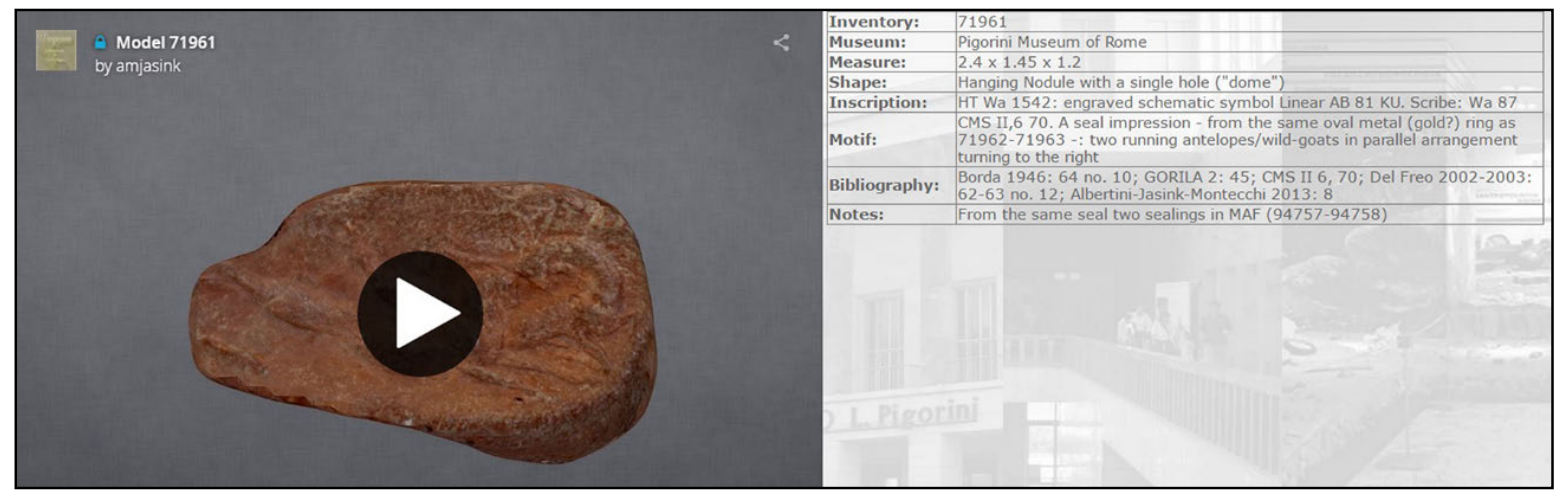

Figure 6. Example of a file concerning a "hanging nodule" from Haghia Triada 
The 3D images, created either with photogrammetry methodologies (Florentine seals) or with laser scanning acquisition (Florentine and Roman sealings) [Remondino 2011] and uploaded on the Sketchfab platform, have been transferred in MUSINT II. To this purpose, a PRO account has been created on the Sketchfab platform in order to make a profile page available with the necessary space to implement and visualize the realized 3D models. For each 3D model, three files have been uploaded (a JPG texture file, an OBJ model file and a MTL material file) to compose a single compressed folder. This reduces the overall dimensions, thus facilitating the uploading in the website. The web pages related to the 3D models have been customized in order to obtain a better interaction between the Sketchfab service and the MUSINT II website. HTML/PHP code has been embedded to recover information from the remote archives. At the same time, a series of tailored database tables have been constructed to manage the amount of data coming from Sketchfab. Finally, SQL code has been written to allow these data to be read and shown in the website [Dionisio et al. 2016]. Tools for processing and editing of 3D meshes as MeshLab can be also found in the EPOCH project results, together with a number of documents and publications about technological strategies to improve the cultural heritage sector [McLoughlin 2007].

\section{EDUCATIONAL SECTION}

In the educational section (Figure 7), initially in Italian, images and contents play a basic role, with the goal of raising an immediate interest in the younger audience. Charming hand-made drawings have been created with traditional techniques and with the support of computer graphics. Six different webpages may be opened in this section. Videos, games and storytelling are proposed to the audience, in a mix that has been variously experienced by other projects [Danks et al. 2007; Ripanti 2015; Antoniou et al. 2016; McLoughlin et al. 2007; the CHESS project at http://www.chessexperience.eu/; the EMOTIVE project at http://emotiveproject.eu/].

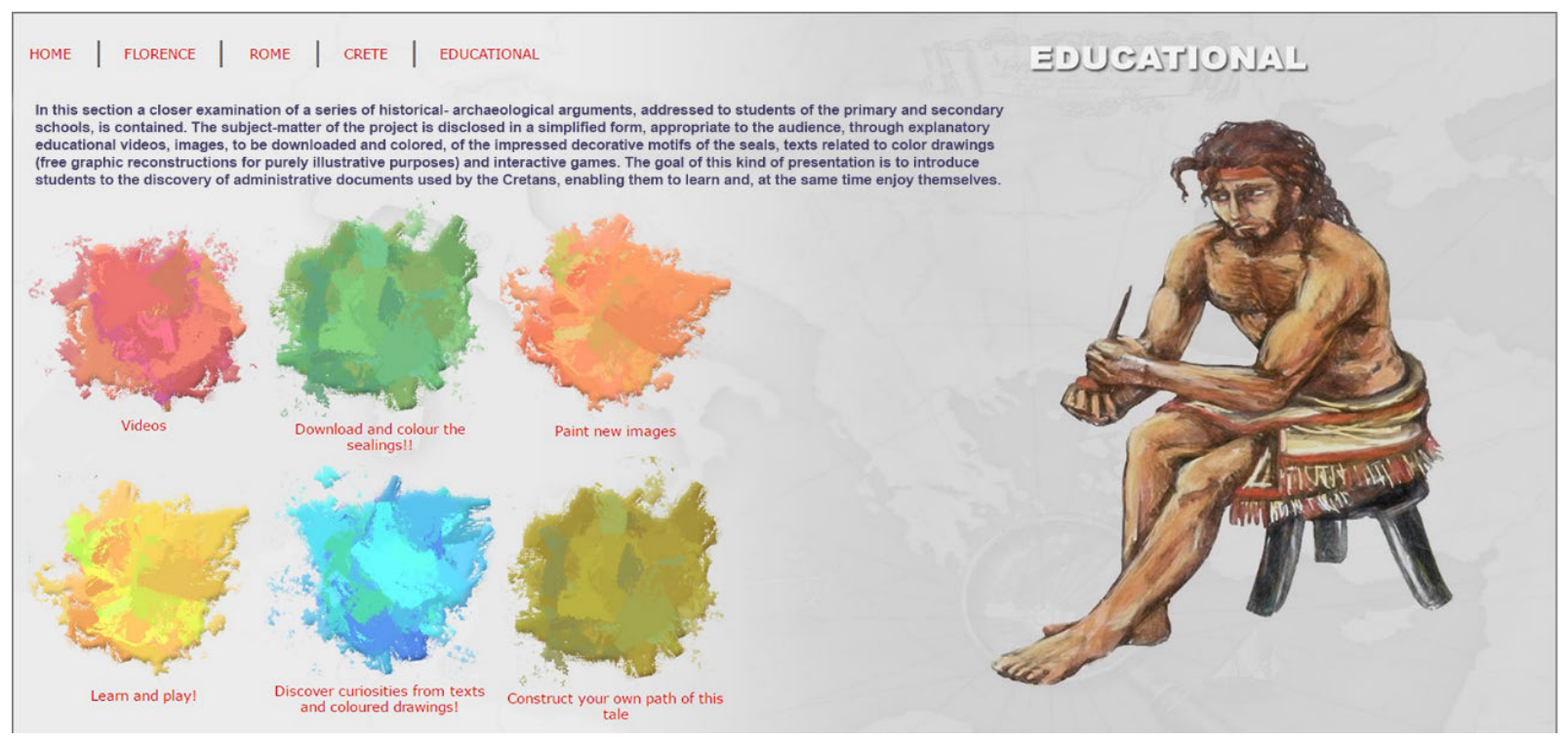

Figure 7. Home page of the Educational section 
a. Videos. Five videos have been inserted here. The files are directly uploaded in the server where the website is running in order to avoid banners or advertising from third-party services. Despite the small amount of disc space, the videos are well balanced, with good resolution and lag-free streaming through the internet. The <video $>$ tag has been used to embed the files in the HTML source code. It allows easy control of some useful properties, such as the file type and the dimension of the window shown on the website.

While the first video is a simplified introduction to explain the meaning of cretulae, seals, sealings, script-signs and their function in the Minoan administration, the second and third ones are brief representations of the photogrammetric technique applied to the 3D digitalization of one of the Florentine seals and of a Florentine sealing. The fourth video shows the lessons for the Montelupo Fiorentino's pupils. The last one is an application of the HDM (Head Mounted Display) technology to popularization; it deals with a multimedia animation on the Minoan Haghia Triada Villa. Total immersion is obtained by stereoscopy and a very large FOV (Field Of View). However, HDM (in particular Oculus Rift DK2) has many other types of sensors, such as gyroscopes, accelerometers and positional tracking systems, which allow for a precise localization and orientation of the user within the virtual environment. HDM affords a visualization able to display more deeply the dynamics of the virtual and actual reality of both the structure of the Villa and the internal environments and the objects of interest. The attention is particularly on sealings. From the point of view of the visualization by a non-specialized audience, this approach makes the available data accessible in a simple, more immediate and lively way [Albertini and Baldini 2016a]. For an actual immersive application and a full display of the video one needs to use tools presently available at the DREAMSlab of the Scuola Normale Superiore in Pisa [Albertini and Baldini 2016b]. Nevertheless, the video in MUSINT II gives a precise idea of the potential of the immersive reconstruction.

b. Download and color the sealings. On the opening webpage the images of the sealings of the two Italian museums appear at once. Each one of them may be downloaded on A4 size paper and colored according to the taste of the pupil. This section is clearly conceived for the primary school pupils who can create a series of posters.

c. Paint new images. This sub-section allows the visitor to work directly on the computer, in addition to the possibilities described above. The webpage contains images of sealings that are only in the Heraklion Museum. Each of them can excite the imagination of the young visitor who, once the seal is chosen, has an empty page available with only a small icon of the selected seal in the top margin. The visitor may draw his own new image of the seal without leaving MUSINT II. A 2D-painting tablet has been implemented and is hosted in the MUSINT II website for the graphic elaboration of the images. It includes drawing tools and color palettes that the visitor may use in order to create and color his own seal. This interactive whiteboard has been made by embedding a drawing application in the webpage HTML source code.

d. Learn and play. The importance of games and gamification is increasingly appreciated by scholars and museum specialists, so a series of activities, using even elaborated games, has been planned to turn museums into interactive places with learning purposes [Barandoni 2016]. Games, either in a pdf format or in interactive environments, can help students to appreciate difficult contents and to learn a scientific lexicon. On the other hand, they can also allow teachers to fill the gaps between what can 
actually be found in school textbooks (normally not updated with recent research) and on the web. In line with these premises, this section contains a series of games (Figure 8), created by Cristiana Barandoni and revised by Isabella Valinoti, which assume an acquaintance with information derived from MUSINT II and, as a consequence, represent an effective and good test on basic knowledge of Minoan Crete. These games are, at the moment, only downloadable in pdf format, but shortly will be transformed into games that users can play online.

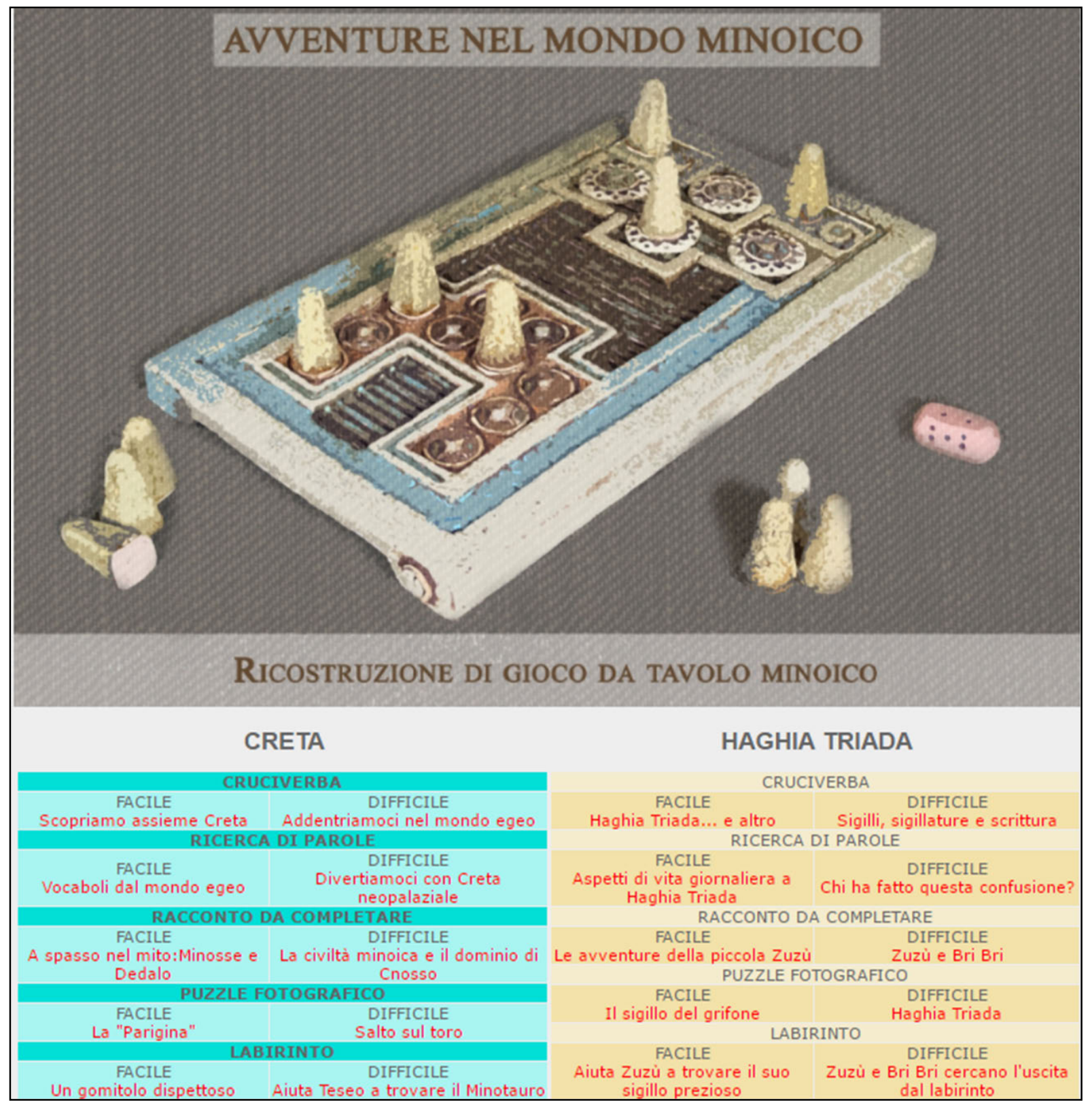

Fig. 8. Home page of "games" 
e. Discover curiosities from texts and colored drawings. In the images of this sub-section some aspects of Minoan life are illustrated. The colored drawings are created with photo editing and digital painting (Figure 9), which we may call the "hyper-realistic current." The hyper-realism in archaeology may be taken as a provocation, but it is a well-suited pathway for a type of communication that is able to overcome the distance between experts and non-specialist observers. The most current techniques, mixed photo editing and digital painting, allow quality effects in the production of historical reconstructions, while being plausible and attractive. Specifically, in the interactive museum content, reconstructions in realistic style offer a modern vision of Minoan life. Starting from the limited information available, the archaeological illustrator goes on to reconstruct the scenes of life and the ancient crafts in the Minoan Aegean world. They may also serve as a guide to explore sub-section c.

f. Construct your own path for this tale. The short tale, La mattina di Zuzù, created by Maria Emanuela Alberti, includes valuable information on daily life in Minoan Haghia Triada and develops as a sort of thriller [see Alberti 2016 for a commentary]. During the whole path, a lot of questions are asked to the young visitor, even about alternative endings of the story. Many new drawings (Figure 10) have been designed by Alberti and Kruklidis for this tale, which represents a useful and amusing conclusion for the didactic section of MUSINT II.

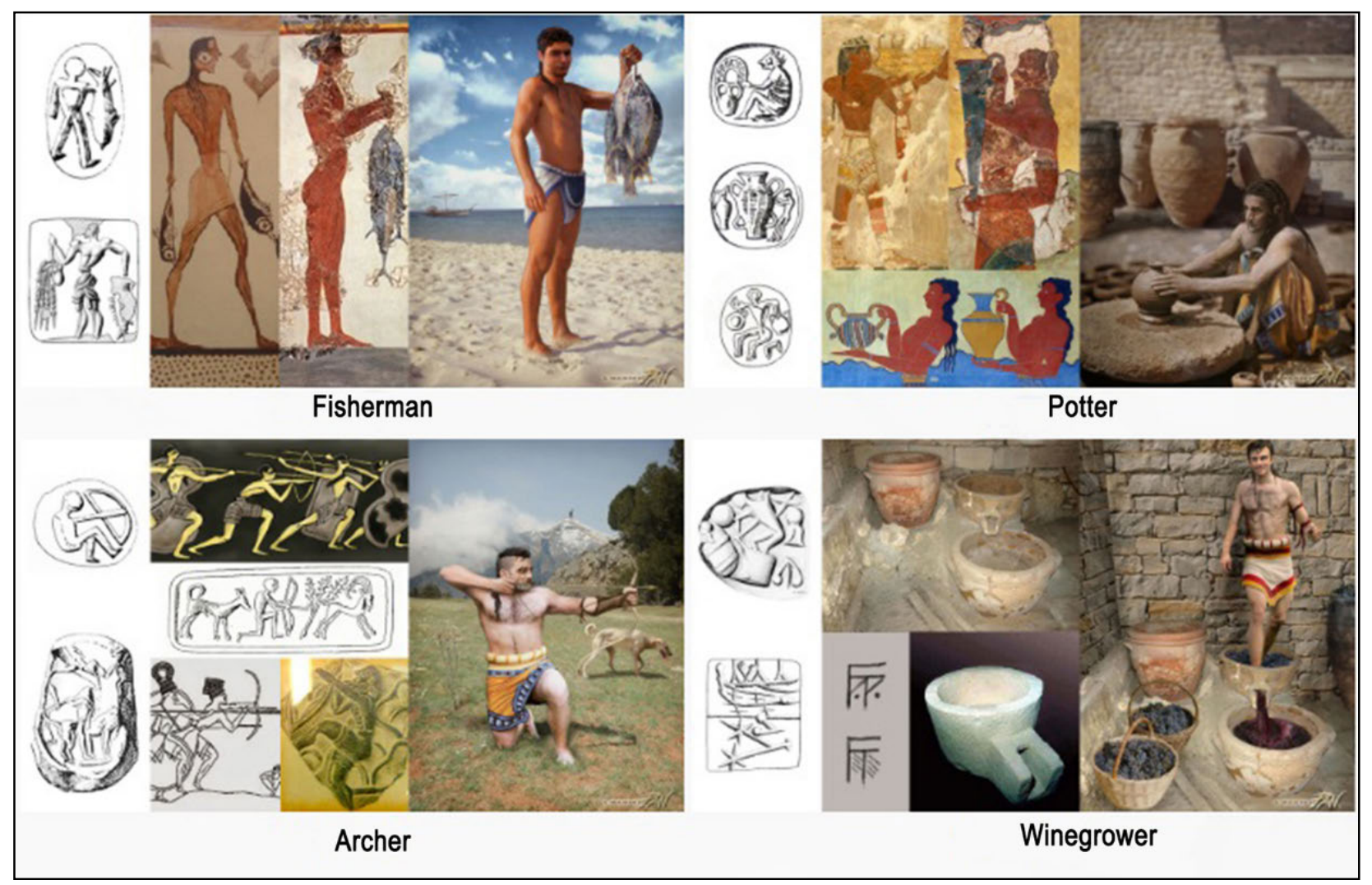

Figure. 9. From Minoan seals and frescoes to a modern representation of craftsmen at work. 
1:294 A. M. Jasink et al.

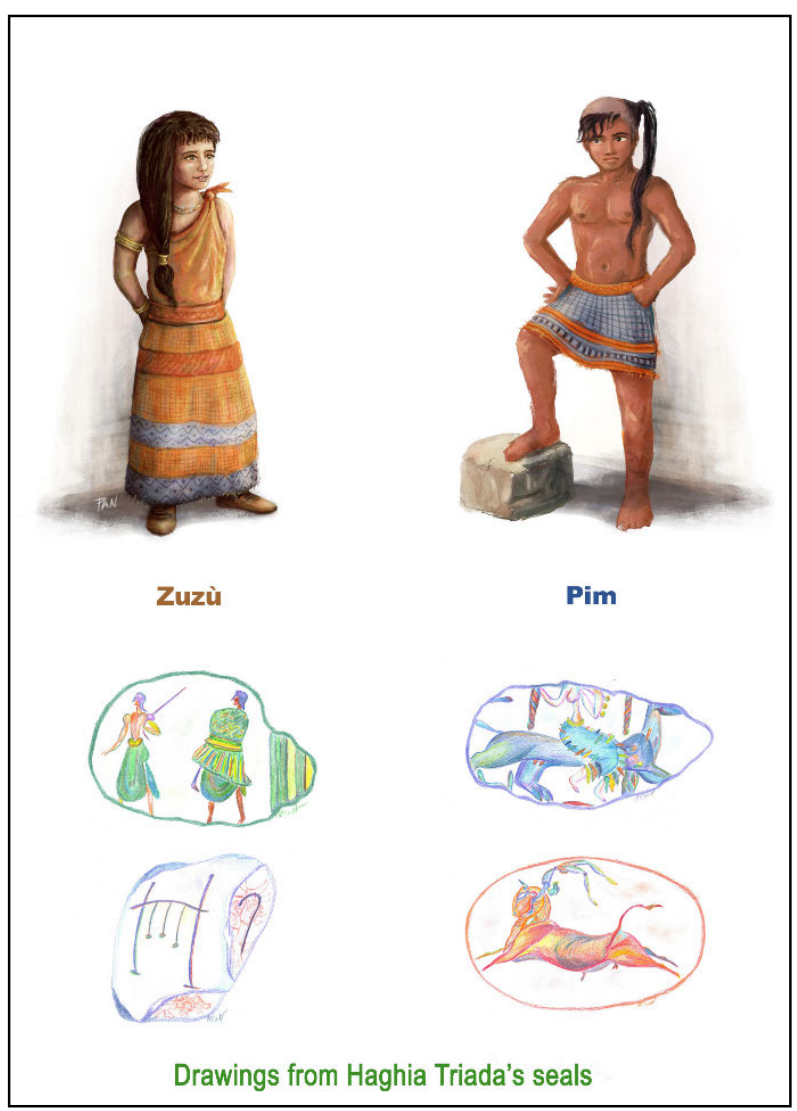

Figure 10. Drawings by E. Alberti and P. Kruklidis from the tale La mattina di Zuzù

\section{CONCLUSIONS}

The purpose of this project is to offer a new analytic and, at the same time, a synthetic vision open to a wide audience, from researchers to young students, of one of the most important sites of Minoan Crete, Haghia Triada, and its administrative documents. The project has been developed in the form of a Museum that includes the presentation of the whole collections of sealed documents stored in Heraklion and in the two Italian museums, the latter also as 3-D models. In addition to the timely analysis of the individual documents and of the relationships between them, the purpose of the project is to offer to the visitor a wider perspective on the archaeological discoveries and historical context.

The database about the whole corpus of cretulae of Haghia Triada represents an important achievement and may be a starting point for new research. The educational section has been implemented with games, drawings, questions and a story.

For four years (2014 - 2017), MUSINT has been the basis of workshops held at the primary school of Montelupo Fiorentino with pupils and teachers. Pupils have been thoroughly exploring the materials of the virtual museum and have been using them as source of inspiration for a number of creative 
re-elaborations, including drawings, puzzles, games, short oral presentations and short acting scenes. A final celebration of the success of these MUSINT workshops took place in the school last May, and saw the participation of more than 200 pupils, with their teachers and parents, both from the higher classes that have been involved in the workshops, and from lower classes, that will start the experiment next year. Everybody considered these workshops an important educational opportunity, to improve pupils' knowledge of antiquities, and their creative and critical skills, and to offer a valuable occasion for social interaction among them. Through these workshops, we learned that interaction with the contents of the virtual museum and creative activities were the most successful among pupils and the most effective in building their historical knowledge. So we decided to implement the games section and the illustrations of MUSINT. The next step we plan for MUSINT is indeed focused on storytelling, with fixed characters exploring various myths of ancient Greece in comparison with the archaeology of Bronze Age. As reported above, MUSINT II is accessible both from DBAS (Data Bases about Aegean Subjects): dbas.sciant.unifi.it (website included in the home page of SAGAS Department of the University of Florence as www.sagas.unifi.it/cmpro-v-p-376.html) and from www.aegean-museum.it/ (a website linked to the first one and containing the whole corpus of databases visible from DBAS). Moreover, MUSINT II may be accessed directly from www.aegeanmuseum.it/musint2/it/.

More detailed information on MUSINT II, including extended references on the various scientific and technical aspects of the project, can be found in Jasink and Dionisio, eds., 2016.

\section{REFERENCES}

CMS II 6 = Corpus der minoischen und mykenischen siegel, Band II, 6. Die Siegelabdrüche von Aj. Triada und anderen zentral- und ostkretischen fundorten. Berlin: Gebr. Mann Verlag, 1999.

GORILA 2 = Godart, L., Olivier, J.-P. (1979) Requeil des Inscriptions en Linéaire A. Vol. 2: nodules, scellés et rondelles édités avant 1970 (Études Crétoises XXI,2). Paris.

Maria Emanuela Alberti. 2016. L'impatto del "racconto" interattivo sull'insegnamento della storia. In Anna Margherita Jasink \& Giulia Dionisio, eds., 53-66. Firenze University Press, Florence, Italy.

Maria Emanuela Alberti et al. Forthcoming. A Multivariate Use of Digital Cultural Heritage: Online Resources for Archaeology in the DBAS-MUSINT Websites (University of Florence, Italy).

Niccolò Albertini \& Jacopo Baldini. 2016a. L'applicazione dell' oculus rift nelle ricostruzioni archeologiche: l'esempio di Haghia Triada. In Anna Margherita Jasink \& Giulia Dionisio, eds., 4752.

Niccolò Albertini \& Jacopo Baldini. 2016b. Il laboratorio DREAMSLab e le sue applicazioni alle scienze dell'antichità In Anna Margherita Jasink \& Giulia Dionisio, eds.,121-125.

Angeliki Antoniou et al. 2016. Capturing the Visitor Profile for a Personalized Mobile Museum Experience: an Indirect Approach. In Proceedings of the 24th ACM Conference on User Modeling, Adaptation and Personalisation (UMAP 2016), Workshop on Human Aspects in Adaptive and Personalized Interactive Environments (HAAPIE). Halifax, Canada.

Alessandro Artusi et al. 2010. The 11th International Symposium on Virtual Reality, Archaeology and Intelligent Cultural Heritage (VAST) Paris, France, 2010. Eurographics Association, 2010.

Cristiana Barandoni. 2016. Serious games e gamification: analisi sul potenziale del gioco per la fruizione e la valorizzazione dell'archeologia egea attraverso MUSINT. In Anna Margherita 
Jasink \& Giulia Dionisio, eds., 149-165.

Michael Danks et al. 2007. Interactive Storytelling and Gaming Environments for Museums: The Interactive Storytelling Exhibition Project. In K. Hui et al., eds. Technologies for E-Learning and Digital Entertainment. Edutainment 2007. Lecture Notes in Computer Science, vol. 4469. Berlin, Heidelberg: Springer, 104-115.

François Djindian. 2007. The virtual museum; an introduction. In Paola Moscati, ed., 9-14.

Giulia Dionisio \& Anna Margherita Jasink. 2016. Teaching new technological methodologies applied to ancient history: the profitable example of the Municipal Archaeological Museum and the primary school of Montelupo Fiorentino, Italy. In: CHNT 20. Proceedings of the 20th International Conference on Cultural Heritage and New Technologies. Wien: eBook Edition.

Giulia Dionisio et al. 2016. Funzione e divulgazione dei modelli 3D all'interno del museo interattivo. In Anna Margherita Jasink \& Giulia Dionisio, eds., 35-40.

Maria Economou. 2006. Museums and New Technologies. London.

Cristian Faralli. 2016. La progettazione del sito web di MUSINT II. In Anna Margherita Jasink \& Giulia Dionisio, eds., 13-19.

Erik Hallager. 1996. The Minoan Roundel and other Sealed Documents in the Neopalatial Linear A Administration. Vol. I (Aegeum 14).

Sorin Hermon \& Franco Nicolucci, eds. 2007. Communicating Cultural Heritage in the 21st century. The Chiron Project and its Research Opportunities. Budapest: Archaeolingua.

Anna Margherita Jasink \& Luca Bombardieri, eds. 2009. Le Collezioni Egee del Museo Archeologico Nazionale di Firenze. Firenze: Florence University Press.

Anna Margherita Jasink \& Giulia Dionisio, eds. 2016. MUSINT 2 Nuove esperienze di ricerca e didattica nella museologia interattiva. Firenze: Florence University Press.

Anna Margherita Jasink et al. , eds. 2011. MUSINT. Le Collezioni Archeologiche Egee e Cipriote in Toscana. Ricerche ed esperienze di museologia interattiva. Firenze: Florence University Press.

Federica Mancini. 2008. Usability of virtual museums and the diffusion of cultural Heritage. UOC Universitat Oberta de Catalunya, 2008.

Jim McLoughlin et al., eds. 2007.Technology strategy, management and socio-economic impact. Heritage Management Series. Volume 2. Budapest.

Paola Moscati. 2007. Virtual Museums and Archaeology. The contribution of the Italian National Research Council. Firenze.

Irina Oberländer-Târnoveanu. 2008. Museum and the Internet. Presenting Cultural Heritage Resources Online. Budapest: Archaeolingua.

Denis Pitzalis et al. 2007. 3D techniques to create interactive virtual museums: The state of the art in the epoch noe, in Proceedings of the Second International Conference on Computer Graphics Theory and Applications GRAPP (AS/IE). Vol. 2. Barcelona, Spain, 197-203.

Fabio Remondino. 2011. Heritage Recording and 3D Modeling with Photogrammetry and 3D Scanning. Remote Sensing 3/6 (2015), 1104-1138.

Francesco Ripanti. 2015. Archeologo cantastorie. In Cinzia Dal Maso \& Francesco Ripanti, eds. Archeostorie. Manuale non convenzionale di archeologia vissuta. Milano: Cisalpino, 2015: 181188.

Soheil Sotoodeh et al. 2008. UPGRADE and IMODELASER: Tools and Best Practice for 3D Data Acquisition and Processing for $\mathrm{CH}$. In David Arnold et al, eds. Different Environments in EPOCH 
MUSINT II $\quad 1: 297$

Conference on Open Digital Cultural Heritage Systems, February 2008: 1-7.

Kay M. Stanney \& Kelly S. Hale. 2014. Handbook of virtual environments: Design, Implementation and Applications. CRC Press.

Received March 2017; revised July 2017; accepted August 2017.

Studies in Digital Heritage, Vol. 1, No. 2, Publication date: October 2017 